\title{
Correspondence
}

\section{Occurrence of amyotrophic lateral sclerosis among Gulf War veterans}

To the Editor: I recently read an article $^{1}$ by authors affiliated with the United States Department of Veterans' Affairs and the United Kingdom Ministry of Defense. It provides data relevant to the first report of an excess of amyotrophic lateral sclerosis (ALS) cases in the deployed population. ${ }^{2}$ The relevant text ${ }^{1}$ is as follows:

The findings of the ALS study have had to be qualified by two considerations:

(i) the results could have been influenced by ascertainment bias because they were based on just seven additional cases of ALS among Gulf War veterans in a study of 2.5 million participants; and

(ii) the mortality rate of Gulf War veterans due to ALS has not yet been found to be elevated. ${ }^{3}$

I had not previously read or heard the statement that the entire claim of excess incidence of ALS in deployed veterans hinged on seven additional cases of ALS. This information was not shared with the readers of Neurology.

In addition, since publication of the first report, ${ }^{2}$ the original authors have confirmed that there was underascertainment in the nondeployed First Gulf War population. ${ }^{4}$ Compared to 67 cases reported in the original article, the range of point estimates derived using three capture-recapture methods was 70 to 81 cases. However, when the authors used the Washington state incidence estimates to derive an upper bound for the number of cases expected in the nondeployed population, it was as high as 90 or 95 . The higher numbers are not reflected in the abstract of the article,${ }^{4}$ and were not used by the authors in recalculating their estimates of the ALS incidence ratio of deployed and nondeployed veterans. They used the lower estimates.

Thus, the authors' claim of excess cases in the deployed population continues to hinge on accepting as valid a lower-thanexpected number in the nondeployed population (relative to a well-ascertained US population), and is supported by methods that sidestep the implications of what appears to be at most a very small absolute number of excess cases.

This additional information appeared belatedly in publications most readers of Neurology may not have read..$^{1,4}$ Furthermore, it is not readily retrievable because it is not reflected in the abstracts of those publications. It supports my original critique. ${ }^{5}$

Carmel Armon, Springfield, $M A$

Disclosure: The author reports no conflicts of interest.

Reply from the Authors: We welcome this opportunity to again respond to the two major points of contention regarding our finding of a twofold increase in risk of ALS among 1991 Gulf War veterans. $^{2}$ These include underascertainment of cases among the nondeployed military personnel (i.e., the control group) and failure to use a general population as the control group.

We are aware that there may have been underascertainment of cases among the nondeployed military personnel who were on active duty during the 1991 Gulf War. Therefore, as Dr. Armon points out, we assessed the presence and magnitude of case underascertainment using capture-recapture methodology. ${ }^{4}$ Details of the analysis can be found in that report.

Only when the number of cases among the nondeployed is projected to be 103 or greater (vs the 67 cases actually identified) does the $95 \%$ confidence limit on the rate ratio become statistically nonsignificant. We contend that this number of cases is unlikely as the rate of ALS in this group would exceed that of a general population, the report of military service being a risk factor for ALS notwithstanding. ${ }^{6}$

Regarding the use of a general population as the control group, military service is an occupation and the first principles of occupational epidemiology indicate that the most appropriate comparison group for a study of ALS among deployed military personnel is another group of military personnel. This is because entry into military service involves a selective process. A general population has not undergone this selective process and does not qualify as an appropriate comparison group. Moreover, as far as we can determine, we have the largest series of ALS cases who are under 55 years of age. Our rates are likely to be the most stable rates available for this age range, making our rate estimates more reliable than those from general populations.

Finally, the lack of an elevated risk of death from this rare disease among Gulf War veterans is a likely consequence of insufficient follow-up time; the most recent mortality study involves only 7 years of follow-up. ${ }^{7}$

We are gratified that while we academicians haggle about methodologic nuances to a degree befitting Talmudic scholars, former VA Secretary Anthony Principi acted on our findings by changing VA policy to make Gulf War veterans with ALS eligible for VA benefits.

Ronnie D. Horner, John R. Feussner, Edward J. Kasarskis, Steven C. Grambow, Cincinnati, $\mathrm{OH}$

Disclosure: The authors report no conflicts of interest.

Copyright $\odot 2007$ by AAN Enterprises, Inc.

\section{References}

1. Hyams KC, Brown M, White DS. Resolving disputes about toxicological risks during military conflict: The US Gulf War Experience. Toxicol Rev 2005;24:167-180.

2. Horner RD, Kamins KG, Feussner JR, et al. Occurrence of amyotrophic lateral sclerosis among Gulf War veterans. Neurology 2003;61:742-749.

3. Rose MR. Gulf War service is an uncertain trigger for ALS. Neurology 2003;61:730-731

4. Coffman CJ, Horner RD, Grambow SC, Lindquist J. VA Cooperative Studies Program Project \#500. Estimating the occurrence of amyotrophic lateral sclerosis among Gulf War (1990-1991) veterans using capturerecapture methods. Neuroepidemiology 2005;24:141-150.

5. Armon C. Occurrence of amyotrophic lateral sclerosis among Gulf War veterans (correspondence). Neurology 2004;62:1027-1028.

6. Weisskopf MG, O'Reilly EJ, McCullough ML, et al. Prospective study of military service and mortality from ALS. Neurology 2005;64:32-37.

7. Kang HK, Bullman TA. Mortality among US veterans of the Persian Gulf War: 7-year follow-up. Am J Epidemiol 2001;54:399-405.

\section{Relationship of vascular risk to the progression of Alzheimer disease}

To the Editor: We read with interest the article by Regan et al. in which the authors discuss the role of vascular risk factors on disease progression in Alzheimer disease (AD). ${ }^{1}$ There was no difference in rate of deterioration between people with and without vascular risk factors except in those who had a cerebrovascular accident. Thus, vascular risk factors may contribute to the expression of $\mathrm{AD}$ initially but are not part of the underlying etiologic process.

These findings correspond with our ongoing study carried out on a consecutive series of patients with $\mathrm{AD}^{2}$ aimed at evaluating the genotype-phenotype effect of well-known vascular risk factors and their possible interactions. Among 230 patients with $\mathrm{AD}, 90$ had been followed periodically through a 1-year follow-up. Each patient underwent a clinical and standardized neuropsychological assessment, including Mini-Mental State Examination (MMSE). Comorbidities (i.e., hypertension, history of cardiovascular events, and diabetes mellitus) were noted according to current clinical criteria.

Venous blood was collected for laboratory analyses and genotyping. Each patient was genotyped for apolipoprotein E (APOE) isoforms ${ }^{3}$ and methylenetetrahydrofolate reductase (MTHFR) C677T and A1298C polymorphisms. ${ }^{4}$ In particular, the relationship between APOE genotype-cholesterol levels and MTHFR polymorphisms-homocysteine levels were considered.

Patients with $\mathrm{AD}$ were classified into two subgroups as presenting progressive cognitive decline through 1-year follow-up (pAD, MMSE 1-year minus MMSE baseline less than 0) or stable 
cognitive functions ( $\mathrm{SAD}$, MMSE 1-year minus MMSE baseline greater than or equal to 0 ). pAD was present in $60 \%$ of patients $(\mathrm{n}=54) ; \mathrm{sAD}$ in $40 \%(\mathrm{n}=36)$. The two groups differed neither for APOE genotype distribution (APOE epsilon $4 ; \mathrm{pAD}$ vs sAD, $46.3 \%$ vs $50.0 \%)$ nor for cholesterol levels $(213.5 \pm 45.8$ vs $224.2 \pm 40.0)$. In $\mathrm{pAD}$ and $\mathrm{sAD}$, MTHFR C677T (TT, $25.9 \%$ vs $22.2 \%$ ) and A1298C (AA, $48.1 \%$ vs $52.8 \%$ ) polymorphism distributions as well as homocysteine levels $(18.2 \pm 12.5$ vs $18.0 \pm 7.5)$ were comparable.

Finally, no significant differences in comorbidities were present. We did not include patients with cerebrovascular accidents during the 1-year follow-up.

In agreement with the observation by Regan et al., these results show that vascular risk factors may play a different role in modulating disease onset or affecting progression. Further studies are needed on larger samples to establish genotype-phenotype effect of the different vascular risk factors on $\mathrm{AD}$ course.

B. Borroni, S. Archetti, M. Ferrari, B.M. Cesana, A. Padovani, Brescia, Italy

Disclosure: The authors report no conflicts of interest.

Reply from the Authors: We thank Borroni et al. for their interest and comments on our article. ${ }^{1}$ We also read their findings that genotypes, certainly in the case of APOE, appear to have a significant effect on disease development ${ }^{5}$ and do not emerge as contributors to the course of the illness. This has been investigated before and certainly evidence does show a complex relationship between APOE and cognitive decline. ${ }^{6}$

These findings are similar to ours in that vascular risk factors do not contribute to disease advancement in $\mathrm{AD} .{ }^{1}$ Vascular risk factors augment the risk for the initiation of the disease, incontrovertibly amplifying it. ${ }^{7}$ This process could be secondary to the change in climate within the brain so as to allow the development of $\mathrm{AD}$.

With the growing body of evidence that this is not due to atherosclerotic disease, ${ }^{8}$ these changes increasingly appear to be caused by an inflammatory response or oxidative stress, triggering the production of amyloid. External factors such as dietary supplements are now being examined and found to be beneficial. ${ }^{9}$

In the particular case of the Mediterranean diet, lack of deterioration was not associated with improved vascular markers ${ }^{10}$ : there was a conferred benefit independent of the vascular protection of the diet which may have been due to the antioxidant effect of the foods involved. Further research aimed at changing the internal environment of the brain to reduce the risk of $\mathrm{AD}$ is urgently needed.

Ciaran E. Regan, Cornelius Katona, Zuzana Walker, G. Livingston, London, UK

Disclosure: The authors report no conflicts of interest.

Copyright ( 2007 by AAN Enterprises, Inc.

\section{References}

1. Regan C, Katona C, Walker Z, Hooper J, Donovan J, Livingston G. Relationship of vascular risk to the progression of Alzheimer disease. Neurology 2006;67:1357-1362.

2. McKhann G, Drachman D, Folstein M, et al. Clinical diagnosis of Alzheimer's disease: report of the NINCDS-ADRDA Work Group under the auspices of Department of Health and Human Services Task Force on Alzheimer's Disease. Neurology 1984;34:939-944.

3. Borroni B, Grassi M, Costanzi C, et al. APOE genotype and cholesterol levels in Lewy Body dementia and Alzheimer disease: investigating genotype-phenotype effect on disease risk. Am J Ger Psychiatry 2007 (in press).

4. Wakutani Y, Kowa H, Kusumi M, et al. A haplotype of the methylenetetrahydrofolate reductase gene is protective against late-onset Alzheimer's disease. Neurobiol Aging 2004;25:291-294.

5. Blair CK, Folsom AR, Knopman DS, et al. Apolipoprotein E genotype and cognitive decline in a middle-aged cohort. Neurology 2005;64:268276

6. Martins CAR, Oulhaj A, de Jager CA, Williams JH. APOE alleles predict the rate of cognitive decline in Alzheimer disease. Neurology 2005; 65:1888-1893.

7. Dik MG, Deeg DJH, Bouter LM, Corder EH, Kok A, Jonker C. Stroke and apolipoprotein E $\varepsilon 4$ are independent risk factors for cognitive decline: a population-based study. Stroke 2000;31:2431-2436.

8. Slooter AJ, Cruts M, Ott A, et al. The effect of APOE on dementia is not through atherosclerosis: the Rotterdam Study. Neurology 2000;54: 2356-2358

9. Schaefer EJ, Bongard V, Beiser AS, et al. Plasma phosphatidylcholine docosahexaenoic acid content and risk of dementia and Alzheimer disease. Arch Neurol 2006;63:1545-1550.

10. Scarmeas N, Stern Y, Mayeux, Luchsinger JA. Mediterranean diet, Alzheimer disease, and vascular mediation. Arch Neurol 2006;63:doi:10.1001/archneur.63.12.noc60109.

\section{Unexpected posthemorrhagic hydrocephalus in patients treated with rFVIIa}

To the Editor: When a new drug is tried, it is important to identify adverse and serious adverse events. The data reported in the article by Subramaniam et al. require follow-up in the analyses of larger trials. ${ }^{1}$ Their data are not comprehensive enough to allow for definite conclusions and the analysis of the data should also be considered.

The authors report only nine cases. They also estimated the expected risk of hydrocephalus based on the modified Graeb criteria and compared it to the observed rate. ${ }^{2}$ Furthermore, the original criteria were not validated, the population in the study was heterogeneous, and the prevalence of intraventricular hemorrhage (IVH) was $30 \%$ and hydrocephalus $41 \% .^{3}$

The modified criteria were derived from a population that seemed more homogeneous (i.e., everybody had IVH); the prevalence of hydrocephalus was not reported and the score was not validated. Sensitivity and specificity were calculated but the absolute true and false positive and negative results were not provided. ${ }^{2}$ With less than $10 \%$ expected probability and 55\% observed rate of hydrocephalus, the authors concluded that rFactor VIIa might have contributed to its development.

The probability of hydrocephalus using likelihood ratios can be easily estimated. ${ }^{4}$ If there was a low pretest probability (prevalence) of hydrocephalus of $10 \%$ and the modified Graeb scores were assessed in the patients of Subramaniam et al., then the risk for hydrocephalus is 1 to $2 \%$. However, if there was a prevalence of hydrocephalus of $50 \%$, then the risk of developing it is 16 to $35 \%$. The original Graeb criteria perform even better with a probability of hydrocephalus of 56 to $72 \%$.

Third, the authors never mention that IVH alone is a risk factor for hydrocephalus; all of their patients with IVH developed it. ${ }^{3,5}$ It would be fairer to compare the observed rate with the rate of hydrocephalus in patients with IVH who were not treated with the drug. Finally, the authors hypothesized that rFactor VIIa impaired clot resolution but provided no evidence to document the presence of the rFactor VIIa in CSF. ${ }^{1}$

Safety is just as important as efficacy. These findings need follow-up but conclusions based on faulty or limited data and assumptions based on invalidated scales can be misleading.

\section{Salvador Cruz-Flores, St. Louis, MO}

Disclosure: Dr. Cruz-Flores has received a grant award from NovoNordisk for participating in the Phase III trial of Factor VIIa in intracerebral hemorrhage.

Reply from the Authors: We thank Dr. Cruz-Flores for his comments. They are well taken but the point of our brief report was to raise the possibility of an untoward adverse event that has not been previously documented. He is correct that we did not measure CSF levels of FVIIa. Obtaining acute CSF samples outside the operating room would have been dangerous. Our article is speculative by design. We await data from the current FAST trial, a phase 3 randomized trial of factor VIIa for acute ICH, to either affirm or refute our hypothesis.

Michael D. Hill, MD, Suresh Subramaniam, MD, Calgary, Canada

Disclosure: The authors report no conflicts of interest. 


\section{References}

1. Subramaniam S, Demchuk AM, Watson T, Barber PA, Hill MD. Unexpected posthemorrhagic hydrocephalus in patients treated with rFVIIa. Neurology 2006;67:1096.

2. Song Z, Yang QD, Zi XH, et al. Modified Graeb criteria for predicting the post-hemorrhagic hydrocephalus in intraventricular hemorrhage. Chin Med Sci J 2004;19:138-141.
3. Graeb DA, Robertson WD, Lapointe JS, Nugent RA, Harrison PB. Computed tomography diagnosis of intraventricular hemorrhage. Radiology 1982;143:91-96.

4. Grimes DA, Schulz KF. Refining clinical diagnosis with likelihood ratios. Lancet 2005;365:1500-1505.

5. Diringer MN, Edwards DF, Zazulia AR. Hydrocephalus: a previously unrecognized predictor of poor outcome from supratentorial intracerebral hemorrhage. Stroke 1998;29:1352-1357.

\section{Helicobacter pylori eradication and L-dopa absorption in patients with PD and motor fluctuations}

To the Editor: Pierantozzi et al. ${ }^{1}$ did not consider that the Helicobacter pylori infections might have been the result of a systemic metabolic abnormality that was the primary cause of the Parkinson disease (PD) and gut dysfunction as in peptic ulceration. ${ }^{2}$

$H$ pylori requires a microaerophilic environment and optimally a much higher $\mathrm{pCO}_{2}$ than that found in the lumen of the gut of healthy subjects in which to thrive in vitro. A common cause of an abnormally elevated gastric intraluminal $\mathrm{pCO}_{2}$ in ambulatory patients is chronic mesenteric ischemia but this may only be present during metabolic stress because of metabolic compensation. ${ }^{3} \mathrm{~A}$ chronically reduced intramucosal $\mathrm{pH}$, often associated with an elevated $\mathrm{pCO}_{2}$, might be the product not only of mesenteric artery disease but also of mitochondrial toxins including translocating gut endotoxin and the cytokines it releases.

An abnormally low intramucosal $\mathrm{pH}$ appears to be an indication of a decline in Daniel Atkinson energy charge ${ }^{4}$; this is thought to be the final common pathway in the evolution of chronic gastrointestinal dysfunction, acute mucosal injury, translocation, and indeed all organ dysfunctions. Gut dysfunction may be necessary for $H$ pylori infection and for any dysfunction or injury that might be induced by $H$ pylori.

While the gut mucosa is considered the canary of the body in the face of acute reductive stress in the critically ill, the brain would seem to be the canary of the body of acute and acute on chronic reductive stress in ambulatory patients. Synaptic vesicles in the brain that concentrate and store catecholamines, including dopamine, also concentrate and store ATP..$^{5}$ It is possible that PD might be a local product of regional or systemic cause of a decline in energy charge including the translocation of endotoxin and the cytokines it releases.

Other gut bacteria, such as $E$ coli, are present in the gut in larger numbers and may contain and release far more endotoxin than $H$ pylori and would be eradicated or reduced in number by the antibiotics used to achieve $H$ pylori eradication. The increase of L-dopa absorption observed in this study may have little or no relation to $H$ pylori eradication.

Richard G. Fiddian-Green, Rickmansworth, UK

Disclosure: The author reports that Tonometric patents have been issued in his name.

Reply from the Authors: Dr. Fiddian-Green states that "Helicobacter pylori infection might have been the result of a systemic metabolic abnormality that was the primary cause of PD and gut dysfunction as in peptic ulceration." We did not address this issue because the objective of our study focused on the reversible $H$ pylori- induced interference with L-dopa intestinal absorption in infected patients with PD.

We think Dr. Fiddian-Green's assertion is unlikely. He believes that events such as chronic mesenteric ischemia or metabolic stress are necessary predisposing conditions for $H$ pylori infection given the peculiar metabolic needs of the organism. This hypothesis is not supported by epidemiology and pathophysiology data on $H$ pylori infection. Epidemiologic studies unequivocally show that
$H$ pylori infection is acquired during childhood ${ }^{6}$ when the predisposing events hypothesized by Dr. Fiddian-Green (i.e., chronic mesenteric ischemia or metabolic stress) are highly improbable.

Concerning the high $\mathrm{pCO}_{2}$ levels required for the organism's survival, there is compelling evidence that they are produced by the strong urease activity present on the organism's surface, which uses the urea of the gastric acid environment as substrate to produce ammonia and $\mathrm{CO}_{2}$, thus creating the optimal conditions for $H$ pylori survival in the gastric lumen. ${ }^{7}$

In addition, Dr. Fiddian-Green comments that $H$ pylori infection itself may represent an innocent bystander and that the improvement of pharmacokinetic and clinical response to L-dopa that we found after eradication may be partially due to the efficacy of $H$ pylori eradication therapy on organisms other than $H$ pylori. This hypothesis cannot be excluded. Nevertheless, as we reported, the relationship between the $H$ pylori-related gastritis/duodenitis relief and the significant clinical improvement observed in $H$ pylori-eradicated patients with PD is certain.

We do consider the possibility that gastrointestinal motility alterations, as frequently found in L-dopa-treated patients with $\mathrm{PD},{ }^{8}$ may allow bacterial overgrowth even in the stomach. ${ }^{9}$ These bacteria, which are generally able to metabolize neutral amino acids, ${ }^{10}$ might in turn directly affect L-dopa intestinal absorption and their elimination due to anti- $H$ pylori antibiotic treatment. Consequently, this could induce a better L-dopa adsorption, but this hypothesis needs to be further evaluated.

A. Pietroiusti, M. Pierantozzi, L. Brusa, S. Galati,

A. Stefani, G. Lunardi, E. Fedele, G. Sancesario,

A. Bergamaschi, A. Magrini, P. Stanzione, A. Galante,

Rome, Italy

Disclosure: The authors report no conflicts of interest.

Copyright $(92007$ by AAN Enterprises, Inc.

\section{References}

1. Pierantozzi M, Pietroiusti A, Brusa L, et al. Helicobacter pylori eradication and L-dopa absorption in patients with $\mathrm{PD}$ and motor fluctuations. Neurology 2006;66:1824-1829.

2. Fiddian-Green RG. H pylori: cause or effect? Available at: http:// www.gutjnl.com/cgi/eletters/35/8/1033\#385.

3. Otte JA, Geelkerken RH, Oostveen E, Mensink PB, Huisman AB, Kolkman JJ. Clinical impact of gastric exercise tonometry on diagnosis and management of chronic gastrointestinal ischemia. Clin Gastroenterol Hepatol 2005;3:660-666.

4. Fiddian-Green RG. Irreversible shock, gastric intramucosal pH and energy charge. Available at: http://adc.bmjjournals.com/cgi/eletters/78/ 2/155\#1417.

5. Bear MF, Connors BW, Paradiso MA. Neuroscience: exploring the brain. Third edition. Baltimore: Lippincott Williams \& Wilkins; 2006.

6. Rowland M, Daly L, Vaughan M, Higgins A, Bourke B, Drumm B Age-specific incidence of Helicobacter pylori. Gastroenterology 2006; 130:65-72.

7. Sachs G, Weeks DL, Wen Y, Marcus EA, Scott DR, Melchers K. Acid acclimation by Helicobacter pylori. Physiology 2005;20:429-438.

8. Hardoff R, Sula M, Tamir A, et al. Gastric emptying time and gastric motility in patients with Parkinson's disease. Mov Disord 2001;16: 1041-1047.

9. Dominquez-Munoz JE. Testing the abnormalities of gastroduodenal function in functional dyspepsia. Dig Dis 2001;19:195-200.

10. Barker HA. Amino acid degradation by anaerobic bacteria. Annu Rev Biochem 1981;50:23-40.

\section{Autonomy and ars moriendi}

To the Editor: In a personal history, ${ }^{1}$ Dr. Steven Ringel argues both sides of two distressing cases. Both cases concern adults with decision-making capacity who have expressed a desire to live and for whom life-extending measures-albeit scarce or costly onesare available. Both patients cede decision making to others and, as a consequence, die.

In the main case, the argument attempts the familiar but impossible utilitarian task of weighing presumptions of quality 
against projections of quantity of life. The outcome: a young woman with Friedreich ataxia and end-stage heart failure lets her "overwhelmed" and "exhausted" parents take her home, rather than undergoing a heart transplant.

In an ancillary case, which could be titled "For Love or Money," a man with amyotrophic lateral sclerosis does not go on a ventilator because his wife, despite her deep love for her husband, holds him to his promise not to leave her destitute.

Ethicist Jeffrey Spike once told me humorously that when we are children our parents make our decisions, when we are adults our spouses do, and when we are old our children do. A competent adult does have the right to shift decision making to another person who is willing to accept the burden. Having watched in dismay as that process went awry, however, I vote for encouraging patients like Dr. Ringel's to retain their right to say, "Let's give it a try."2 I believe we should always do all we can to keep patients in charge of such choices.

At the same time, I respect Dr. Ringel's clinical judgment. Some ethical questions are true dilemmas.

David Goldblatt, Penn Yan, NY

Disclosure: The author reports no conflict of interest.

Reply from the Author: I appreciate Dr. Goldblatt's wise reminder of the unintended consequences of shifting decision making away from a patient. We all like to think of ourselves as independent human beings able to make our own decisions. Today's medical technology, which allows us to extend life, and the almost daily discoveries of new cures for illness, certainly foster these feelings of autonomy. But increasingly, modern medical management of chronic medical conditions has created inadvertent dependency. For those with debilitating illnesses, families and caregivers have become essential components of the management team. Chronically ill patients often cannot survive without their help.

The President's Council on Bioethics has been looking into the ramifications of mutual dependency in health care decisionmaking. ${ }^{3}$ Ironically, its recent report discourages an individual's use of living wills and advance directives to control his or her own treatments and death. Instead, it argues that it is more effective for someone with a chronic or terminal illness to acknowledge dependency by asking a loved one to assume power of attorney for medical decisions. David Brooks, a New York Times columnist, refers to this paradigm shift as a "declaration of dependence."

Having advised patients and families who face progressive and often fatal neuromuscular disorders for many years, I can attest to the overwhelming demands on family members taking care of someone chronically ill and their feelings of inadequacy. Sometimes a family member who is not ready to let go of a loved one wants us to keep that person alive. For a lot of reasons, at times we comply, perhaps even because of our own fear of death. In other situations, as in the cases I portrayed, caregivers face the realities of their loved ones' diseases and come to accept impending death before the person who is dying.

We regularly witness complexity and chaos in the lives of our patients and their families. As we struggle to help them, we must not substitute our judgment for all involved. But as the President's Council of Bioethics reminds us, our modern technological brand of medicine forces us to reexamine the advice we offer to patients and their families as they make treatment choices that can sustain or end their lives. And in that reexamination, we need to accept that there are, unfortunately, limits to autonomy.

Steven P. Ringel, Denver, $C O$

Disclosure: The author reports no conflicts of interest.

Copyright $@ 2007$ by AAN Enterprises, Inc.

\section{References}

1. Ringel SP. Autonomy and ars moriendi. Neurology 2006;67:1101-1102.

2. Goldblatt D. Who's listening? Advance directives aren't always directive. Neurologist 2001;7:180-185.

3. Taking Care: Ethical Caregiving in our Aging Society. The President's Council on Bioethics, Washington, DC, September 2005. Available at: http://www.bioethics.gov/reports/taking_care/fulldoc.html. Accessed October $21,2006$.

\section{Corrections}

\section{Correspondence: Diagnostic evaluation of clinically normal subjects with chronic hyperCKemia}

There was an error in the byline to the Correspondence by R.H. Walker et al. in response to "Diagnostic evaluation of clinically normal subjects with chronic hyperCKemia" (Neurology 2007;68:535-536). The byline of the Correspondence should read as follows:

Ruth H. Walker, MB, ChB, PhD, Bronx, NY; Hans H. Jung, Zurich, Switzerland; and Adrian Danek, MD, Munich, Germany

\section{Correspondence: Coronary artery disease is associated with Alzheimer disease neuropathology in APOE4 carriers}

There were errors in the disclosures in the Correspondence regarding "Coronary artery disease is associated with Alzheimer disease neuropathology in APOE4 carriers" (Neurology 2007;68:471). The disclosures should have read as follows:

To the Editor, by Christine M. Hulette and Kathleen Welsh-Bohmer: Supported by NIA P50 AG05128 and R01 AG07198 and Glaxo Smith-Kline.

Reply from the Authors, by M. Schnaider Beeri, M. Rapp, J.M. Silverman, J. Schmeidler, H.T. Grossman, J.T. Fallon, D.P. Purohit, D.P. Perl, A. Siddiqui, G. Lesser, C. Rosendorff, and V. Haroutunian: Supported by NIA K01 AG023515-01A2 (Dr. Beeri), P01 AG-02219 (Dr. Haroutunian), and P50 AG-05138 (Dr. Sano). The authors report no conflicts of interest. 


\section{Neurology}

\section{Correspondence: Coronary artery disease is associated with Alzheimer disease neuropathology in APOE4 carriers \\ Neurology 2007;68;1086-1086-a \\ DOI 10.1212/01.wnl.0000262727.94824.76}

This information is current as of March 26, 2007

\section{Updated Information \&}

Services

Permissions \& Licensing

Reprints including high resolution figures, can be found at: http://n.neurology.org/content/68/13/1086.2.full

Information about reproducing this article in parts (figures,tables) or in its entirety can be found online at:

http://www.neurology.org/about/about_the_journal\#permissions

Information about ordering reprints can be found online:

http://n.neurology.org/subscribers/advertise

Neurology ${ }^{\circledR}$ is the official journal of the American Academy of Neurology. Published continuously since 1951, it is now a weekly with 48 issues per year. Copyright . All rights reserved. Print ISSN: 0028-3878. Online ISSN: 1526-632X.

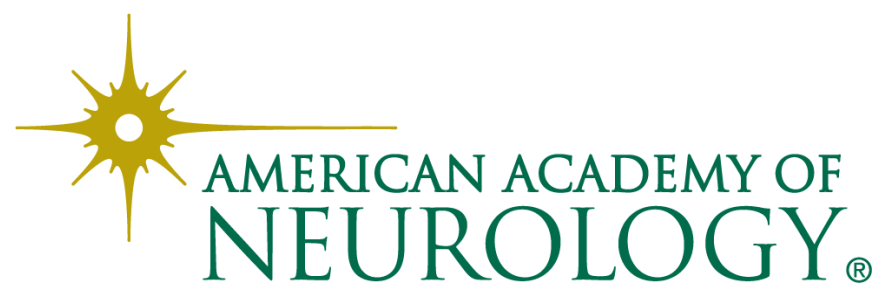

